\title{
AlNGaN HEMT T- gate Optimal Design
}

\author{
zhangxiaowei $^{1,2}$ Jiakejin $^{1}$, Wangyuangang ${ }^{2}$, Fengzhihong ${ }^{2}$, Zhaozhengping ${ }^{2}$ \\ ${ }^{1}$ Hebei University of Technology, College of information engineering, Tianjin, 300130 \\ ${ }^{2}$ China Electronics Technology Group 13 Institute, Key Laboratory of special integrated circuit, shijiazhuang,050000 \\ a Zhangxiaowei0323@126.com
}

\begin{abstract}
The GaN HEMT is widely used in high-frequency aspects, use the T-gate to reduce gate resistance is one of the most effective methods to improve the the device maximum oscillation frequency ( $f$ max). But $f_{\text {max }}$ is very sensitive to $T$-gate size, improper selection may reduce $f_{\text {max }}$, Therefore, in order to reduce the cost of production, it is necessary to select appropriate simulation T-gate size. We have worked out AlGaN/GaN HEMT with gate length of $0.17 \mu \mathrm{m}$ and $f_{\max }$ values $110 \mathrm{GHz}$. Accuracy of the simulation model is verified by experiment. Then detailed simulates the impact of the $T$-gate size and we obtain ptimized $T$-gate size range.
\end{abstract}

Keywords- frequency characteristics; GaN HEMT ; T-gate size; Simulation model

\section{INTRODUCTION}

GaN HEMT performs superiority in the aspect of high frequency and power performance, and is widely used in the microwave and power applications, it is also one of research hotspots. As to high frequencies, the most direct and effective method is reducing gate length. APA Optics Corporation Khan et al proposed AlGaN/GaN HEMT with $0.25 \mu \mathrm{m}$ gate length, $11 \mathrm{GHz}$ cut-off frequency $\left(\mathrm{f}_{\mathrm{T}}\right)$ and $35 \mathrm{GHz}$ maximum oscillation frequency $\left(\mathrm{f}_{\max }\right)$ in 1994 , from then on scholars shrink the gate length to improve the AlGaN/GaN HEM frequency continuous. In 2000, Micovic et al of HRL reduced gate length to $50 \mathrm{~nm}$, and its $\mathrm{f}_{\mathrm{T}}$ and $\mathrm{f}_{\max }$ reached $110 \mathrm{GHz}$ and $140 \mathrm{GHz}$ respectively. In 2010, Chung et al used T-gate and MBE technologies achieve AlGaN/GaN HEMT with $\mathrm{f}_{\max }$ values $300 \mathrm{GHz}$. However, with the narrowing of gate length, the short channel effect is more and more obvious, and it impact threshold value, frequency, and other characteristics of HEMT. In order to further improve $\mathrm{f}_{\max }$ of HEM, select a suitable T-gate size is a effective way. But if the T-gate size selection improper, it cannot improve device $f_{\max }$, even counterproductive, So in HEMT design process, to clear the influence degree of size of the T-gate to devices $\mathrm{f}_{\max }$, so as to select a appropriate $\mathrm{T}$ gate size. In this paper, combine with existing the tapeout parameters and results, we conduct optimized design simulation of the T-gate.

\section{COMPARISON OF EXPERIMENTAL AND SIMULATION RESULTS OF ALGAN/GAN HEMT}

On the barrier layer of $20 \mathrm{nmAl}_{0.25} \mathrm{GaN}$, to work out $\mathrm{AlGaN} / \mathrm{GaN}$ HEMT with $170 \mathrm{~nm}$ gate length and 400nm gate cap width, the device contains AlGaN back barrier, and the substrate uses sapphire, its $\mathrm{f}_{\mathrm{T}}$ and $\mathrm{f}_{\max }$ reached $50 \mathrm{GHz}$ and $110 \mathrm{GHz}$ respectively, as is shown in Figure 1. In a same size, the experimental and test data comparison shown in Table 1, there exist few difference between them, and verify the accuracy of our model. The models we used include: polarization model, low field mobility University of Bologna model, high field mobility Canali model, band gap model, complex model, thermal electron emission model and so on.

Table 1 Test results and experimental results of AlGaN/GaN HEMT

\begin{tabular}{|c|c|c|}
\hline AlGaN/GaN HEMT & $\mathrm{f}_{\mathrm{T}}(\mathrm{GHz})$ & $\mathrm{f}_{\max }(\mathrm{GHz})$ \\
\hline Test result & 51 & 111 \\
\hline Experimental result & 54 & 116 \\
\hline
\end{tabular}

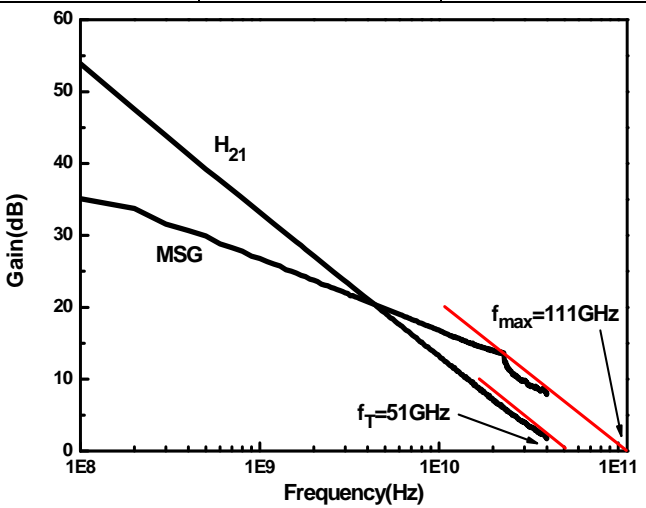

Figure 1 Test figure of frequency characteristics

III. SimUlation AND OptimizATION OF ALGAN/GAN HEMT TGATE SIZE

The structure of AlGaN/GaN HEMT sees at figure 2. Figure 2(b) shows the amplification of the gate. $\mathrm{W}_{\text {gate }}$ and $\mathrm{T}_{\text {gate }}$ is the dimension of the gate head and the thickness respectively. $L_{\text {gate }}$ is the gate length and $H_{\text {gate }}$ is the height of gate root. 


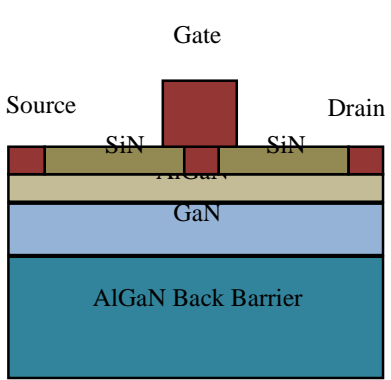

(a)

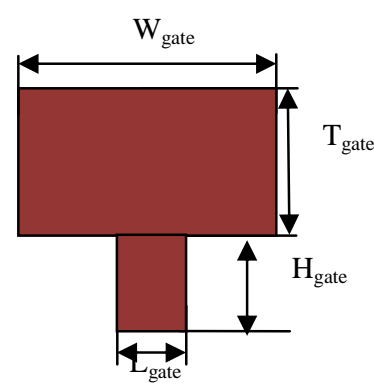

(b)
Figure 2 AlGaN/GaN HEMT:

(a)Device structure (b) The structure of T-gate

1 Optimization of AlGaN/GaN HEMT gate length $\left(\mathrm{L}_{\text {gate }}\right)$ and gate root height $\left(\mathrm{H}_{\text {gate }}\right)$

The relationship of AlGaN/GaN HEMT gate length and frequency is shown in figure 3 . We can see that $f_{T}$ and $f_{\max }$ increase steadily in pace with the decrease of gate length $\mathrm{L}_{\text {gate }}\left(\mathrm{L}_{\text {gate }}>100 \mathrm{~nm}\right)$. When $\mathrm{L}_{\text {gate }}$ is larger than $100 \mathrm{~nm}$, the ratio of gate length and the thickness potential barrier is bigger than 5, the device short channel effect is not obvious. The gate source capacitance and gate-drain capacitance decrease steadily with the decrease of gate length. We can see that the decrease of gate source capacitance $\mathrm{C}_{\mathrm{gs}}$ and gatedrain capacitance $C_{g d}, f_{T}$ and $f_{\max }$ will increase steadily from the posture (1) and posture (2). Therefore, we should decrease gate length under permission of technology when design AlGaN/GaN HEMT.

$$
\begin{aligned}
& f_{\mathrm{T}} \approx \frac{\mathrm{g}_{\mathrm{m}}}{2 \pi\left(C_{g s}+C_{g d}\right)} \\
& f_{\max } \approx \frac{f_{T}}{2 \sqrt{\left(R_{i}+R_{s}+R_{g}\right) g_{d s}+\left(2 \pi f_{T}\right) R_{g} C_{g d}}}
\end{aligned}
$$

As shown in figure 4 , we can see the influence to $\mathrm{f}_{\mathrm{T}} / \mathrm{f}_{\max }$ from $\mathrm{AlGaN} / \mathrm{GaN}$ HEMT gate root height $\mathrm{H}_{\text {gate }}$. The gate source capacitance and gate-drain capacitance decrease steadily with the increase of gate root height, the change touch off the decrease of $\mathrm{f}_{\mathrm{T}}$ and $\mathrm{f}_{\max }$. However, the increasing trend of $\mathrm{f}_{\max }$ become slow down gradually and reach a saturation value reached saturation. On one hand, the reduction of $\mathrm{C}_{\mathrm{gs}}$ and $\mathrm{C}_{\mathrm{gd}}$ decrease steadily with the increase of gate root height. On the other hand, with the decrease of gate capacitance, the degree of influence of parasitic capacitance to $f_{\max }$ increase, the resistance becomes bottleneck to bind up the $f_{\max }$. $f_{\max }$ reach a saturation value reached saturation when $\mathrm{H}_{\text {gate }}$ exceed 70nm.

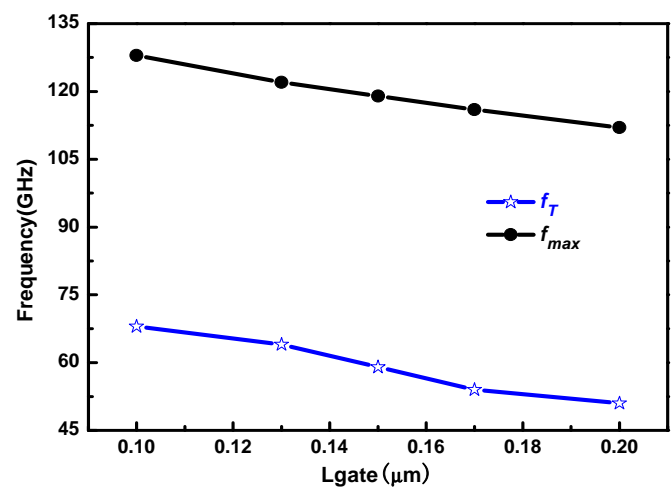

Figure 3 The relationship between AlGaN/GaN HEMT gate length and $\mathrm{f}_{\mathrm{T}} / \mathrm{f}_{\max }$

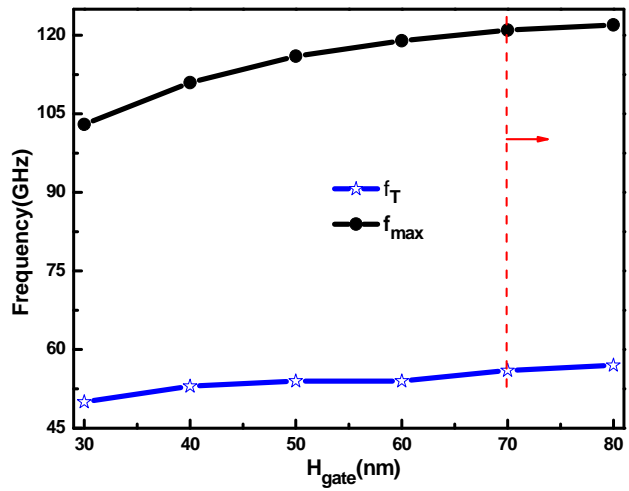

Figure 4 the relationship between AlGaN/GaN HEMT gate root height and $\mathrm{f}_{\mathrm{T}} / \mathrm{f}_{\max }$

2 Optimization of AlGaN/GaN HEMT gate width $\left(\mathrm{W}_{\text {gate }}\right)$ and gate head thickness $\mathrm{T}_{\text {gate }}$

Maintain the $170 \mathrm{~nm}$ gate length and $50 \mathrm{~nm}$ gate root height that have tapped out to study the influence to $\mathrm{f}_{\mathrm{T}} / \mathrm{f}_{\max }$ from $\mathrm{W}_{\text {gate. }}$ The relationship between AlGaN/GaN HEMT gate width and $\mathrm{f}_{\mathrm{T}} / \mathrm{f}_{\max }$ is shown in figure $5 . \mathrm{C}_{\mathrm{gs}}$ and $\mathrm{C}_{\mathrm{gd}}$ decrease steadily with the decrease of Wgate. The change results in the decrease of $\mathrm{f}_{\mathrm{T}}$. The posture (2) shows that the decrease of gate capacitance enforces $f_{\max }$ increase. However, with the increase of gate width, gate resistance increase as well. The change will enforces $f_{\max }$ decrease. Therefore, with the decrease of gate width, $\mathrm{f}_{\max }$ will increase first and will decrease later. It has an excellent value range: $250-300 \mathrm{~nm}$.

Maintain the $170 \mathrm{~nm}$ gate length, the $400 \mathrm{~nm}$ gate width and $50 \mathrm{~nm}$ gate root height to study the influence to $\mathrm{f}_{\mathrm{T}} / \mathrm{f}_{\max }$ from $T_{\text {gate, }}$ as shown in figure 5 . With the increase of Tgate, the gate resistance decreases, however the gate capacitance is essentially the same, so $f_{T}$ practically constant, $f_{\max }$ is increased gradually. However, $\mathrm{f}_{\max }$ gradually become saturated. The reason is as follows: as it shows by the formula (2) in case of $f_{T}$ constant, $\left(R_{i}+R_{s}+R_{g}\right) g_{d s}$ and $2 f_{T} R_{g} C_{g d}$ would affect $f_{\max }$. With the decreasing of gate resistance, 2 fTRgCgd continues to decrease, while $\left(\mathrm{R}_{\mathrm{i}}+\right.$ $\left.\mathrm{R}_{\mathrm{s}}+\mathrm{R}_{\mathrm{g}}\right) \mathrm{g}_{\mathrm{ds}}$ will become saturated. $\left(\mathrm{R}_{\mathrm{i}}+\mathrm{R}_{\mathrm{s}}+\mathrm{R}_{\mathrm{g}}\right)$ become the major factor impact on $f_{\max }$ as the increasingly proportion. $\mathrm{f}_{\max }$ tends to saturation when the gate head thickness $\mathrm{T}_{\text {gate }}$ beyond 500nm. 


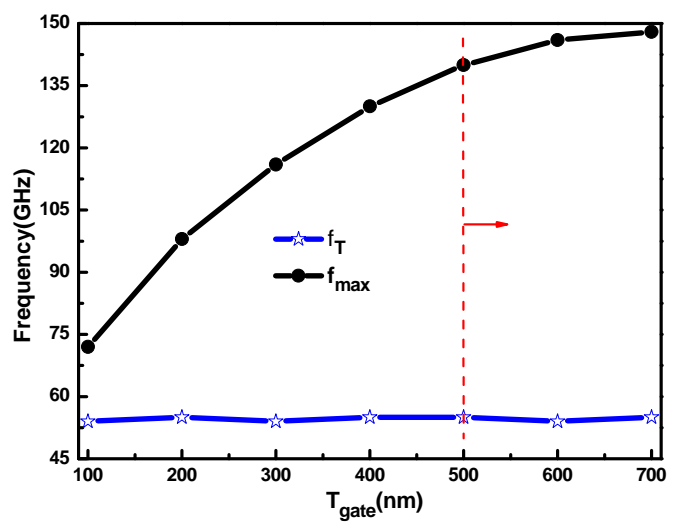

Figure 5 The relationship between AlGaN/GaN HEMT gate width and

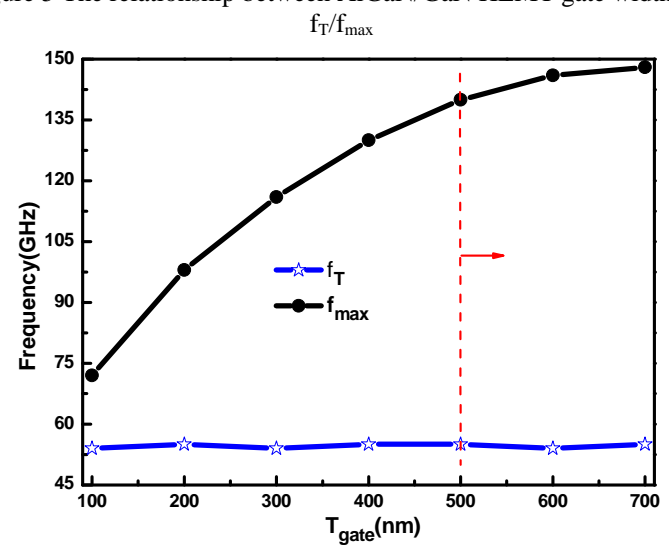

Figure 6 The relationship between AlGaN/GaN HEMT gate head thickness and $\mathrm{f}_{\mathrm{T}} / \mathrm{f}_{\max }$

\section{CONCLUSION}

The accuracy of the simulation model of this article has been verified through experiment firstly, then simulation shows the influences on $\mathrm{f}_{\mathrm{T}} / \mathrm{f}_{\max }$ of the T-gate sizes, provided a reference for the experiment. After Simulation, it comes to conclusions that: the width of the gate head affects $R_{g}$, $\mathrm{C}_{\mathrm{gs}}$ and $\mathrm{C}_{\mathrm{gd}}$, the influence on the $\mathrm{f}_{\max }$ exists an optimal range: $250-350 \mathrm{~nm}$. As the gate root height and gate head thickness increase, $\mathrm{fm}_{\mathrm{ax}}$ increases but gradually become saturated. As gate length $(>100 \mathrm{~nm})$ decrease, $\mathrm{f}_{\max }$ monotonically increasing, According to the process conditions, reduce the gate length as far as possible.

\section{REFERENCES}

[1] Delage,S.L., E.Morvan, N.Sarazin, et.al., Achievement and Perspective of GaN Technology for Microwave Applications, 18th International Conference on Microwaves, Radar and Wireless Communications, Levitas.2010.

[2] Mishra, U.K and Gaas, Status of AlGaN/GaN HEMT Technology - A UCSB perspective. GAAS 2005:13th European Gallium Arsenide and Other Compound Semiconductors Application Symposium, Conference Proceedings, 2005.21-27.

[3] Ma Xiangbai, Hao Yue, Zhang Jincheng, Microwave power, Research progress of AlGaNVGaN HEMT, Electronic Science and technology, 2006

[4] M.A.Khan, J.N.Kuznia, D.T.Olson, et al., Microwave performance of a $0.25 \mathrm{~m}$ gate $\mathrm{AlGaN} / \mathrm{GaN}$ heterostructure field effect transistor, Appl.Phs.Lett., 1994,65(9):1121-1123.

[5] Micovi, M., N.X.Nguven, P.Janke, et al., GaN/AlGaN high electron mobility transistors with $\mathrm{f}(\mathrm{tau})$ of $110 \mathrm{GHz}$. Electronics Letters, 2000. 36(4).358-359.

[6] Chung , J.W, Hoke, W.E, Chumbes, E.M, et al., AlGaN/GaN HEMT With 300-GHz fmax, Electron Device Letters, 2010. 31(3). 195-197.

[7] O Breitschadel, L Kley, H Grabeldinger, et al., Short-Channel effects in AlGaN/GaN HEMTs, Materials Science and Engineering:B, 2001,82(1).238-240.

[8] Jessen, G. H, Fitch, R.C, Gillespie, J.K, et al., Short-Channel Effect Limitations on High-Frequency Operation of AlGaN/GaN HEMTs for Tgate Devices, Electron Devices, 2007,54(10). 2589-2597. 